\title{
FRANCISCO TOPA
}

\section{ENTREVISTA ${ }^{1}$}

\section{O ensino de literaturas africanas}

Francisco Topa é Professor Associado do Departamento de Estudos Românicos da Faculdade de Letras da Universidade do Porto, lecionando nas áreas de Literatura e Cultura Brasileiras, Crítica Textual, Literaturas Africanas de Língua Portuguesa e Literaturas Orais e Marginais. Doutorou-se em Literatura, em 2000, na mesma Faculdade, com uma tese sobre o poeta barroco

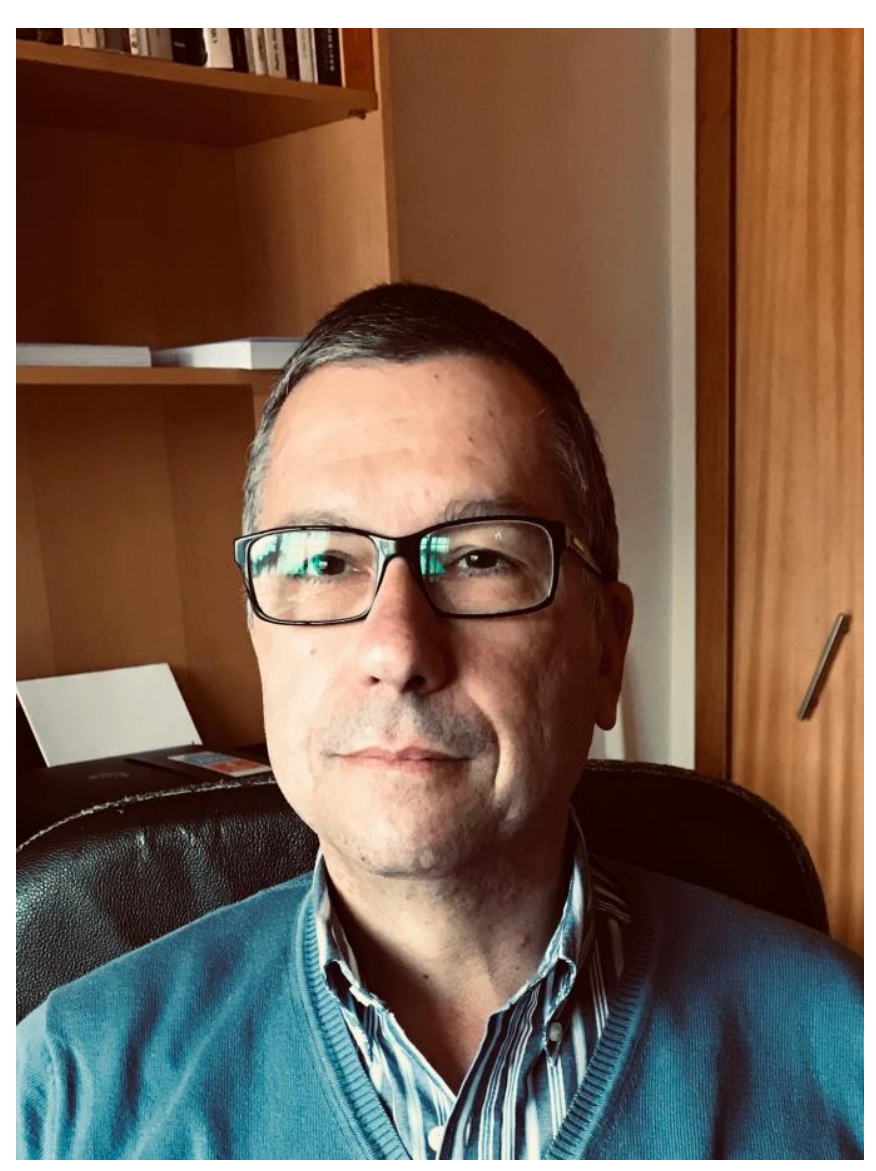
Gregório de Matos. Obteve em 2016, também na FLUP, o título de Agregado em Estudos Literários, Culturais e Interartísticos, especialidade de Literatura e Cultura. Sua investigação tem estado dirigida para a literatura portuguesa e brasileira dos séculos XVII e XVIII, para as literaturas africanas de língua portuguesa e para algumas áreas da literatura oral e marginal. Tem participado em congressos da especialidade, em Portugal e no estrangeiro, e é autor de vinte livros e de cerca de uma centena de artigos e outras publicações nos domínios mencionados. Entre os livros dedicados às literaturas africanas, destacam-se:

\footnotetext{
${ }^{1}$ Entrevista realizada por Joelma Siqueira e Dirceu Magri em fevereiro de 2019. Revista pelo autor em 25/4/2019. Editada pelos entrevistadores. 
FERREIRA, José da Silva Maia Ferreira. Espontaneidades da minha alma. Edição facsimilada. Introdução e organização por Francisco Topa. Porto: Sombra pela cintura, 2018.

MARECOS, Ernesto. Juca, a matumbola e outros textos angolenses. Introdução e edição por Francisco Topa. Porto: Sombra pela cintura, 2018.

40 anos de literaturas africanas na FLUP: da preia à baixa-mar? Org. Francisco Topa. Porto: Sombra pela Cintura, 2017.

Luandino por (re)conhecer: uma entrevista, estórias dispersas, bibliografia. Introdução, recolha e edição por Francisco Topa. Porto: Sombra pela cintura, 2014. 172 pp. ISBN: 978-989-962069-8.

"Luuanda" há 50 anos: críticas, prémios, protestos e silenciamento. Introdução, recolha e edição por Francisco Topa. Porto: Sombra pela cintura, 2014. 324 pp. ISBN 978-989-96206-74.

CUNHA DANTAS, Guilherme da. Contos singelos e outros textos. Introdução, edição e notas de Francisco Topa e Tânia Solano Ardito. Porto: Sombra pela cintura, 2013. 227 pp. ISBN 978989-96206-6-7.

JOELMA SIQUEIRA: Prezado professor Francisco Topa, ficamos muito honrados de contar com essa entrevista para o presente número da Revista Jangada e gostaríamos de começar perguntando-lhe o que vem a sua mente quando se depara, no âmbito dos estudos literários e culturais, com a expressão "vozes d'além mar"?

FRANCISCO TOPA: A honra e o prazer são meus. Para ser franco, não gosto da expressão, embora compreenda o seu uso. Faz-me lembrar coisas um tanto desencontradas: uma revista missionária com esse título que havia em Portugal e o Vozes d'África, de Castro Alves. Nestes dois últimos casos, a intenção é aparentemente boa: levar ajuda, caritativa, a uma África que suscita pena por ser África, por ter na "terra de Suez" a "corrente que me ligaste ao pé”. Ora, do meu ponto de vista, quando dizemos "vozes d'além mar", estamos - consciente ou inconscientemente - a reproduzir esse modelo: os escritores africanos são "vozes" que nos chegam de "além", de um outro mundo.

DIRCEU MAGRI: Tomando-se como base o conceito de transferência cultural, cunhado pelo Prof. Michel Espagne, em que toda passagem de um objeto cultural de um contexto para outro implica, necessariamente, uma alteração de sentido e uma nova dinâmica de ressemantização, como as literaturas africanas de língua portuguesa convivem com os influxos portugueses? 
FRANCISCO TOPA: Creio que a questão varia de acordo com a época e com o espaço (e, obviamente, segundo cada autor). Nos primeiros tempos do período colonial terá sido relativamente pacífica, mas já no último quartel do século XVII, num autor como António de Oliveira de Cadornega, que escreveu a História Geral das Guerras Angolanas, percebemos bem o alcance da teoria: já não se trata de mera "importação" - a língua e o modelo de discurso tornaram-se outros. A partir daí, teremos sempre (talvez mesmo até hoje, já em tempo póscolonial) dois modelos: a transferência acompanhada de uma adaptação, mais ou menos "antropofágica", e uma transferência mais seguidista, que tenta ir ao encontro dos interesses do poder (seja ele a metrópole ou o mercado global). É isso, creio eu, que explica em certa medida o sucesso, fora de África, de certos autores africanos e o apagamento de outros.

JOELMA SIQUEIRA: Em 2015, o senhor produziu o relatório "Literatura Angolana" para provas de agregação na área de Estudos Literários, Culturais e Interartísticos na Universidade do Porto. Tendo em vista que o senhor também leciona nas áreas de Literatura e Cultura Brasileiras, Crítica Textual e Literaturas Orais e Marginais, teria algum comentário sobre a escolha dessa unidade curricular para o referido relatório?

FRANCISCO TOPA: Poderia de facto ter escolhido outra área, mas pareceu-me que essa era aquela que, na Faculdade em que trabalho, precisava de ser reforçada. Tínhamos (e temos) dois professores cujo doutoramento foi feito noutros domínios e que só começaram a trabalhar sobre as literaturas africanas por imposições de serviço e há relativamente pouco tempo; por outro lado, as literaturas africanas estavam de algum modo desvalorizadas (na grade curricular, nas oportunidades de financiamento e de carreira); por fim, os estudos literários não tinham sido capazes de acompanhar o esforço que estava a ser feito noutras áreas das ciências sociais e humanas. Além disso, e de um ponto de vista pessoal, tratava-se de uma oportunidade para refletir sobre o que tinha vindo a fazer nos anos anteriores e de discutir publicamente um conjunto de questões teóricas e práticas que me interessavam.

DIRCEU MAGRI: Ao longo da circulação das ideias literárias, a literatura portuguesa, seja em relação à forma, seja por convergência temática, bebeu nas fontes clássicas greco-latinas. 
Como as literaturas africanas materializam esse diálogo com a cultura clássica, há muito entranhada na língua e literatura portuguesas?

FRANCISCO TOPA: De um modo geral, essa circulação passou por duas fases. A primeira teve como mediador Portugal, como país colonizador, seja através do modelo de educação transplantado para os territórios, seja através dos seus autores. No primeiro poeta angolano com livro publicado, José da Silva Maia Ferreira, a referência ainda é o Mantuano, isto é, Vergílio, juntamente com os poetas portugueses do Renascimento. Do mesmo modo, em Cabo Verde, a geração anterior à Claridade tem uma evidente matriz clássica, adquirida em grande medida através da formação oferecida pelo seminário-liceu de S. Nicolau. A partir de meados do século $\mathrm{XX}$, creio que esse diálogo passou a resultar da reflexão que cada autor foi fazendo sobre a identidade, pessoal e nacional, e sobre o caminho que as literaturas locais deviam seguir. Em alguns casos, esse diálogo é ainda mais forte e mais consequente do que nos tempos anteriores. Veja-se o caso de Luandino Vieira, que reinventa a língua portuguesa mantendo e às vezes reforçando a sua matriz latina: "De sanzala e outros, advogados todos eu conheço.", escreveu ele em João Vêncio, cujo protagonista declara só querer o "galo bélico", isto é, o De Bello Gallico, de César!

JOELMA SIQUEIRA: O senhor é membro do Centro de Estudos Africanos da Universidade do Porto (CEAUP). Que contribuições esse Centro tem realizado para os estudos das literaturas africanas na instituição, tanto na graduação quando na pós-graduação?

FRANCISCO TOPA: O CEAUP é o grande baluarte dos estudos africanos na Universidade do Porto, funcionando não apenas como centro de investigação científica de referência, mas também como meio de divulgação e, à sua escala, como polo diplomático. Foi graças ao CEAUP que foi possível criar, em meados dos anos 90, um mestrado em Estudos Africanos e, uma década depois, um curso de doutoramento na mesma área. A sua revista, Africana Studia, e os colóquios que organiza ou apoia são também um importante instrumento de atuação do centro. Apesar disso, os estudos literários são - mea culpa também - o seu elo mais fraco: somos poucos investigadores e não conseguimos ainda criar uma rede suficientemente alargada que inclua, mas também que ultrapasse, todos os espaços lusófonos africanos. 
DIRCEU MAGRI: É fato que estamos familiarizados com uma África, ou uma ideia de África, como invenção do Ocidente. Por outro lado, temos Elisio Macamo, escritor moçambicano, afirmando que os escritores africanos são os melhores sociólogos que se têm no momento. Em que medida a literatura produzida hoje na África consegue refutar preconceitos e clichês há muito aderidos às sociedades africanas, qual seja, como expressam uma África que podem chamar de sua?

FRANCISCO TOPA: É verdade que os autores africanos são hoje mais conhecidos e mais lidos, e de algum modo também mais reconhecidos (pela crítica, pela media, pela academia e por uma série de outras instituições). Apesar disso, a minha visão é pessimista: os autores promovidos são sobretudo os que refletem a visão de África mais consentânea com a visão do Ocidente, são aqueles que quiseram e souberam criar uma literatura de exportação, muitas vezes em linha com a agenda teórico-política das academias europeias e americanas. Do meu ponto de vista, isso empobrece e distorce a nossa visão de África e das literaturas africanas.

JOELMA SIQUEIRA: Ensinar Literaturas Africanas em Portugal assemelha-se à experiência de ensinar literatura brasileira? Poderia nos contar um pouco como tem sido sua experiência com essas grades curriculares?

FRANCISCO TOPA: Não, é bastante diferente, até por causa do ponto de partida. De um modo geral, os alunos de literatura brasileira sabem já um pouco do Brasil, da sua história, da sua cultura e dos seus autores. No caso dos países africanos, não: ignoram completamente tudo o que lhes diz respeito e, de um modo geral, creem que podem ler os seus autores ignorando o lugar de onde eles falam, como se a circunstância de escreverem numa língua que aparentemente é a mesma servisse de chave. É necessário, pois, fazer um trabalho propedêutico que lhes forneça alguns instrumentos básicos, mas também teóricos e concetuais, que os leve a ler estas literaturas de um modo diferente daquele que usam para a literatura portuguesa. É necessário também combater um certo desprezo - às vezes inconsciente - face àquilo que é africano. 
DIRCEU MAGRI: No texto "Sonhar em casa", , a respeito da obra de Jorge Amado, Mia Couto afirma: "O Brasil - tão cheio de África, tão cheio de nossa língua e da nossa religiosidade - nos entregava essa margem que nos faltava para sermos rio." No Brasil, cunhamos o termo "literatura afrodescendente", que se debruça sobre a construção de identidades afrodescendentes e o papel da memória. Sob viés comparatista, como o senhor trabalha a intersecção dessas duas literaturas de língua portuguesa, a produzida na África e a afrodescendente brasileira?

FRANCISCO TOPA: Nunca trabalhei sobre a literatura afrodescendente brasileira, embora tenha lido alguns autores e alguns ensaios sobre o tema. Contudo, com base no que li, fiquei com dúvidas sobre o conceito: não me parece que a matriz afro vá muito além da questão da pele e de uma memória mais folclórica do que efetiva. Mas é provável que se trate de um equívoco meu.

JOELMA SIQUEIRA: Nos últimos, anos o senhor vem realizando eventos relevantes sobre as literaturas africanas, como "De Luuanda (1964) a Luandino (2014)"; "Baobá, pinheiro, ácer: Manuel dos Santos Lima, escritor orgânico"; “40 anos de estudos literários africanos na FLUP”. Por favor, comente um pouco sobre a repercussão desses eventos e os materiais bibliográficos que têm originado.

FRANCISCO TOPA: Temos tentado aproveitar algumas datas para chamar a atenção para as literaturas africanas e para mobilizar os seus estudiosos. Neste ano de 2019, vamos assinalar em setembro os 40 anos da morte de Agostinho Neto e suscitar o debate em torno da sua eventual herança sobre os Prémio Camões Africanos (Craveirinha, Pepetela, Luandino, Arménio Vieira, Mia Couto e Germano Almeida). Os encontros têm corrido bem, do ponto de vista académico, e os trabalhos daí resultantes creio que são positivos. Falta porém continuidade e falta romper com um certo isolamento que, no meu entender, condiciona as literaturas africanas. A expressão "terceiro mundo" deixou de ser usada, mas o conceito continua vivo na mente de muitas pessoas. Enquanto não conseguirmos alterar esse estado de coisas, enquanto África continuar a ser vista como um espaço - ainda por cima único e homogéneo (!) - à espera

\footnotetext{
${ }^{2}$ COUTO, Mia. E se Obama fosse africano? Ensaios. São Paulo: Companhia das Letras, 2011.
} 
da caridade ocidental, enquanto os seus grandes escritores (da Nigéria à Argélia, do Mali ao Quénia, da África do Sul a Moçambique) continuarem à margem, à espera de ser traduzidos, lidos e estudados, não será de esperar grandes mudanças.

JOELMA SIQUEIRA e DIRCEU MAGRI: Caro professor, certos da sua contribuição para a Revista Jangada, agradecemos muitíssimo. 